- The majority of dental nurses found it difficult to assess their educational requirements but felt they would benefit from continuing professional development.

- There was a marked discrepancy between general dental practitioners' and dental nurses' perceptions and opinions about continuing education for dental nurses within the practice.

- Only $9 \%$ of dental nurses had worked at the same practice for more than 10 years.

\title{
Perceptions, attitudes and opinions of general dental practitioners and dental nurses to the provision of lifelong learning for the dental team
}

\author{
P. Mercer, ${ }_{1}^{1}$ H. Bailey ${ }^{2}$ and P. Cook $^{3}$
}

This paper reports on a survey of the attitudes of general dental practitioners (GDPs) and dental nurses to continuing education. This has become the subject of increased policy attention in recent years. The Adult Dental Health Survey of 1998 indicated that in order to meet the increase in requirements for the provision of Dental Health Services in the UK the Professions Complementary to Dentistry (PCDs) would be required to play a greater role in the delivery of dental services. In 2001, the Government undertook a review of the dental workforce, with a remit to look at ways to modernise the education and training system for dentists and the other members of the dental team.

As the regulatory body of the dental profession, the General Dental Council's (GDC) role is to protect patients. In 2003 it announced, 'To provide better standards of patient care and better career prospects for PCDs the GDC is extending registration to the wider dental team. This will mean that as well as dentists, dental hygienists and dental therapists, other groups of PCDs, including dental nurses and dental technicians, will also need to register with us.'2 Subsequently the GDC was granted powers by Parliament to take forward mandatory registration for dental nurses. In the changes to the Dental Act, the title PCD was changed to Dental Care Professionals (DCPs) to better reflect the role of this important group of individuals, and the

${ }^{*}-3$ Department for NHS Postgraduate Medical and Dental Education, Willow Terrace Road, University of Leeds, Leeds, LS2 9JT

${ }^{*}$ Correspondence to: Mrs P. Mercer

Email:phoebe_mercer@hotmail.com

\section{Refereed Paper}

Accepted 21 June 2006

DOI: $10.1038 /$ bdj.2007.540

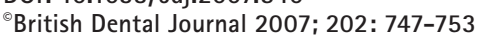

term DCPs will be used in the rest of this paper. As of July 2006, the GDC will hold two registers, one for dentists and one for all other members of the dental team. At the end of a two-year transition period, all dental nurses will need NVQ Level 3 or the National Certificate to be included on the new register. This will allow those dental nurses who have the equivalent of two years' full-time chairside experience but who do not hold a formal qualification an opportunity to prove their competence and gain admittance to the register. Registration brings with it new responsibilities and accountability for DCPs. Hew Mathewson, President of the GDC, stated, 'There is one ethical code for all registrants. All PCDs have a professional responsibility to put patients first'.

The maintenance of professional knowledge and skills and the co-operation with other members of the dental team and other healthcare colleagues in the interests of patients are two of the six key principles which all dental professionals are expected to apply to their daily work. To maintain the knowledge and skills of the dental workforce, providers of postgraduate dental education including postgraduate dental deaneries have a duty to provide appropriate educational and training opportunities. Cannell, ${ }^{3}$ in his case study of the delivery of postgraduate dental education, concluded that when providing training for the dental team, knowledge of the training needs of the potential learning group can help ensure relevance of the content and design of the learning events. There is, however, very little information available on the attitudes and opinions of dental nurses and their perceptions of their own educational needs.

\section{ATTITUDE SURVEY}

In the context of the move towards mandatory registration for dental nurses, the Yorkshire Deanery was keen to find out how it could best provide continuing education for DCPs. A postal survey of GDPs, dental nurses and hygienists serviced by the Yorkshire Deanery was undertaken to elicit the appropriate information. 


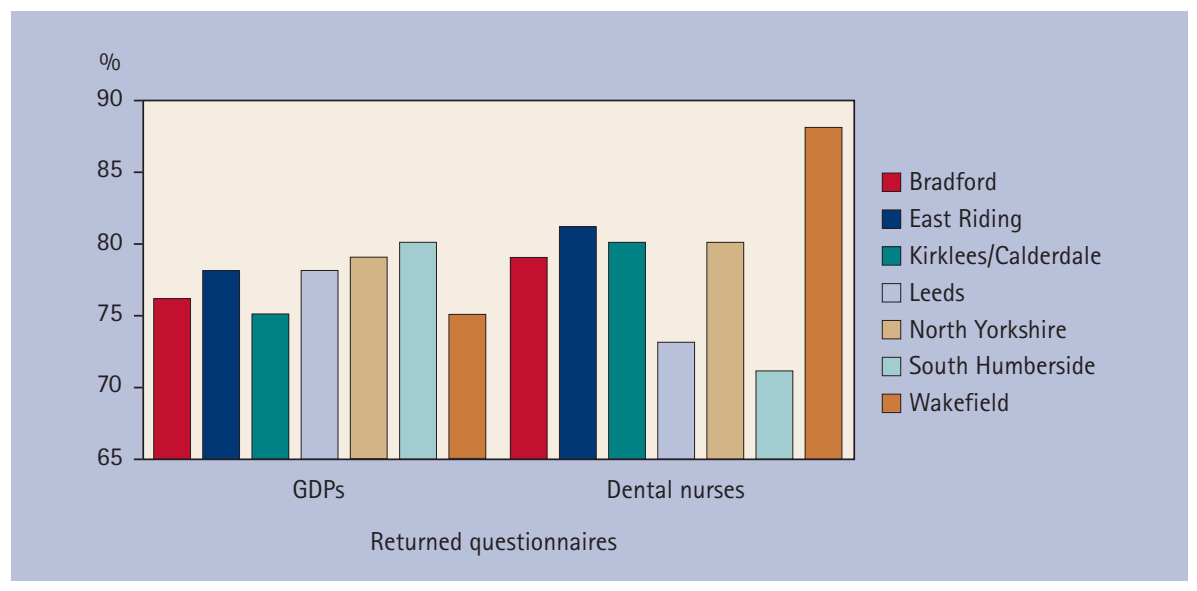

Fig. 1 Sample spread questions targeted specifically at this group. The data from both sets of questionnaires were analysed using the computer-based Statistical Package for the Social Sciences (SPSS) V11.

\section{RESULTS}

The returned questionnaires were fairly evenly spread across the seven regions with a return ratio between $75 \%$ and 80\% for GDPs and 71\% and 88\% for dental nurses (Fig. 1).

\section{PRACTICE, GDP AND DENTAL NURSE CHARACTERISTICS \\ Practice}

Six of the 131 practices participating in the GDP sample did not have questionnaires returned by the dental nurses in the practice. Conversely, questionnaires were not returned from GDPs in seven of the 132 practices involved in the nurses' sample. Of all practices participating in the study, 23\% were single-handed, 31\% had two dentists, $21 \%$ had three dentists and 25\% had four or more dentists. Of all GDPs 38\% worked in large practices (four dentists or more) and 12\% worked alone (Fig. 2). Twenty percent of practices employed one dental nurse, 23\% had two dental nurses, 23\% had three dental nurses and 34\% included four or more dental nurses. In large practices, $69 \%$ of the dental nurses were qualified and approximately 50\% in singlehanded and other practices held a dental nurse qualification. Five percent of GDP respondents restricted their practice to a single speciality and of these, 11 specialised in orthodontics and two in implant dentistry. The remaining 95\% worked in general practices but with $10 \%$ of these involved in some specialist work. Only one respondent said he was a fully private practitioner and 7\% that they were fully NHS practitioners. When asked the ratio of NHS to private more than half, $57 \%$, indicated that at least three-quarters of their patients were NHS.

\section{GDP}

The majority of respondents (65\%) were principals in the practice with the remainder associates, except one, who was an assistant. The age range and length of time in practice were fairly evenly spread throughout the sample. Only $24 \%$ of respondents had further qualifications, with more than half of these holding the MFGDP. A range of other qualifications
The questionnaire used both open and fixed response questions and was
The dental nurses' questionnaire followed a similar format to the GDPs' with 


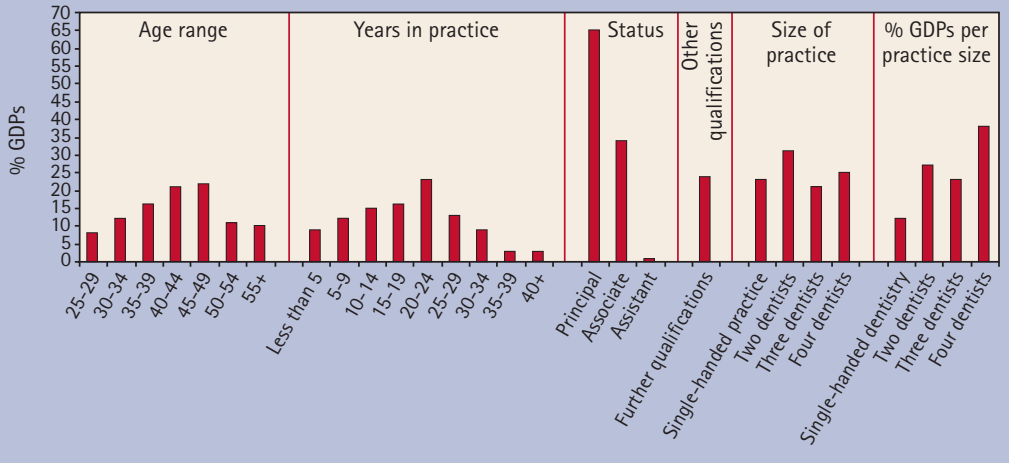

General dental practitioner characteristics

Fig. 2 GDPs' profiles $(n=249)$

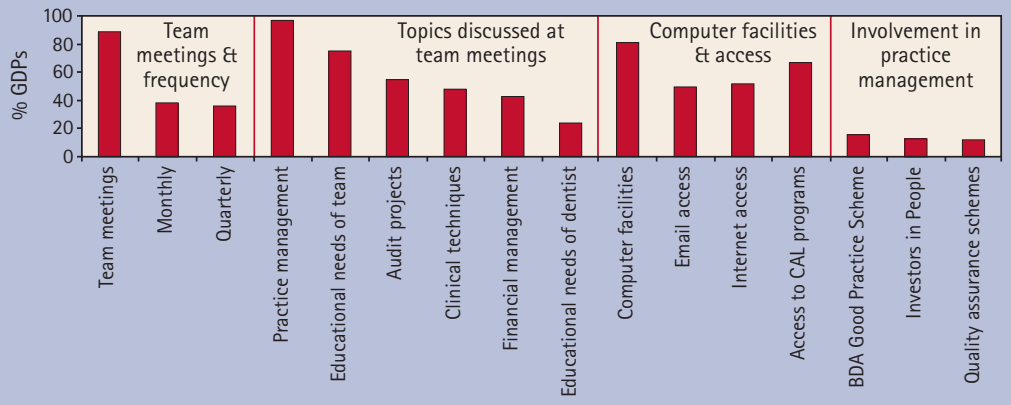

Fig. 3 GDPs' involvement in the practice $(n=249)$

was indicated including six dentists qualified in orthodontics and five holding a university masters degree (Fig. 2).

Forty-six percent of dental practitioners indicated that they had other professional commitments. Of this group 58\% were involved in peer review, 27\% with local dental committees, 25\% with the BDA, 15\% with the FGDP (UK), 12\% were vocational trainers and 11\% were involved in undergraduate teaching. Fifteen percent of respondents held other posts including clinical assistant, clinical demonstrator, hospital practitioner and senior dental adviser.

\section{Dental nurse}

The age range followed a normal curve but length of time in practice varied with $41 \%$ of dental nurses reporting less than 10 years. Sixty percent worked full time, 44\% indicating that their current job was the only dental nurse position they had held. Of this latter group, only 20\% had worked at the same practice for more than 10 years whilst $28 \%$ had been in the job for one year or less. One respondent said she was an examiner for the Certificate in Dental Nursing. Fifty-four percent had obtained the National Certificate while $29 \%$ stated that they had more than one qualification (Fig. 4). These included certificates for radiography, oral health education, dental sedation, and orthodontic nursing. Further analysis showed that the larger practices employed more nurses with qualifications, 69\%, in comparison to single-handed or two-dentist practices $50 \%$ and 52\% respectively.

\section{KNOWLEDGE OF FACILITIES IN THE PRACTICE}

GDPs

Over $80 \%$ of GDPs had computer facilities in the practice but surprisingly only 50\% said they had Internet and email access. There were no significant differences between the over 40 and under 40 age groups with regard to use of computers. During the previous five years a number of respondents, 45\%, were involved with practice management schemes including the BDA Good Practice Scheme (16\%), Investors in People (13\%), Computer Management Systems (13\%) and the Denplan Excel scheme (9\%) (Fig. 3).

Eighty-nine percent of respondents indicated that practice meetings were held for the whole dental team with 38\% meeting monthly and 36\% quarterly. Practice management and the educational needs of other team members were the most popular topics followed by audit projects, clinical techniques and financial management. Only $24 \%$ of respondents said the educational needs of the dentist were discussed at team meetings (Fig. 3).

\section{Dental nurses}

Seventy-seven percent of respondents indicated there were computer facilities in the practice but only 25\% said they had access to email and Computer Assisted Learning and 29\% to the Internet. Seventy-seven percent indicated that practice meetings were held at work for the whole dental team with only $3 \%$ indicating that they were not encouraged to give their opinions on matters under discussion. Meetings were held monthly (38\%), quarterly (23\%) and when required (7\%). Other set times listed for team meetings included daily, weekly, two-weekly, twice per year and yearly.

The majority of nurse respondents (59\%) who replied to the question about topics discussed at team meetings said the smooth running of the practice was the main topic. Patient and staff complaints (23\%), and staff training, holidays and sick leave (21\%) followed this. Only 13\% indicated discussion on crossinfection control and 11\% on patient care and health and safety. Sixty-four percent suggested a range of other topics including new procedures, reception skills, missed appointments, cardio-pulmonary resuscitation and communication skills.

\section{KNOWLEDGE OF CONTINUING EDUCATION IN THE PRACTICE \\ GDPs}

Fifty-two percent implied they had a problem finding courses for their nurses to attend but when asked if other members of the dental team had attended any educational courses in the previous three years, 92\% stated that their dental nurse had been on courses and $48 \%$ that the hygienists had attended courses.

Twenty-one percent indicated there was an appraisal system in place for dentists and 51\% that there was an appraisal system for dental nurses. A quarter of respondents said they had personal development plans (PDPs) for the academic year 2004/5 and $16 \%$ that their 


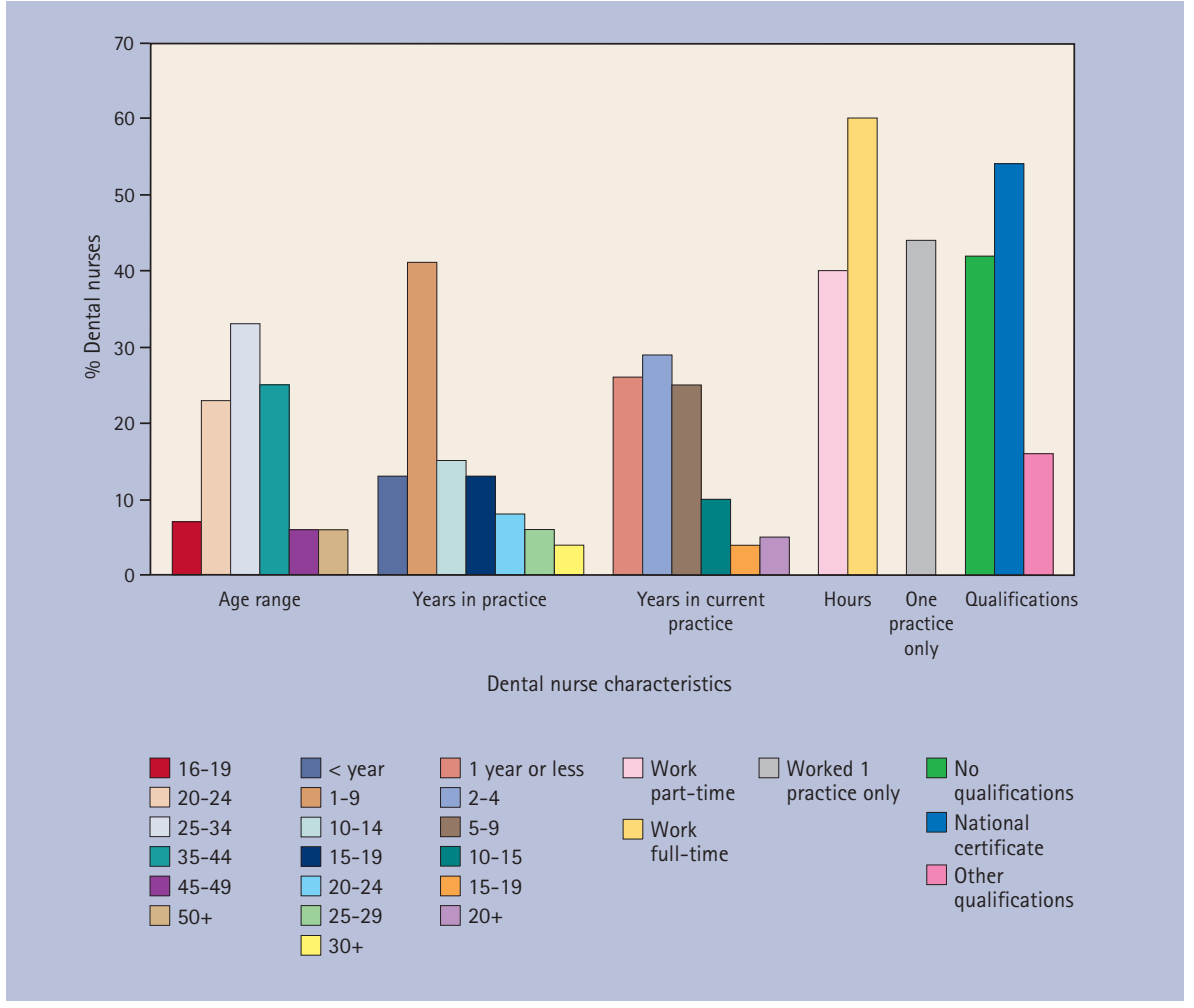

Fig. 4 Dental nurse characteristics $(n=410)$

dental nurses had PDPs. Only 24\% said they had a formal training plan drawn up for the dental team.

The question on preference for nurse training showed that overall 26\% preferred to train their dental nurse themselves, whilst $32 \%$ felt attendance at courses was preferable and $41 \%$ wanted a mixture of the two. There was no difference between the younger end of the age spectrum and the older end with regard to training preferences but in two-dentist practices $40 \%$ preferred to send their nurses on courses while $35 \%$ preferred to train the nurse themselves. Fifty-nine percent of respondents thought in-house training was more cost effective. Just over half (51\%) thought that other members of the dental team were involved in providing training for the dental team. This mainly took the form of experienced staff working with less experienced members and the practice manager or senior receptionist overseeing and organising training.

Practice meetings were the most common method used in the practice to update the knowledge and skills of dental nurses (78\%), closely followed by experienced staff working with less experienced (77\%), staff teaching sessions (63\%), delivery of training in the practice by somebody from outside (57\%), and the use of either video, computer assisted learning or long distance learning (34\%). Only $12 \%$ of respondents used TEAMWORK, the national teaching and learning programme designed for staff training within the dental workplace, for training purposes.

\section{Dental nurses}

Sixty-two percent of dental nurses indicated that they had attended at least one educational course in the previous three years and 54\% that they had training in the practice during the previous year (Fig. 5). Practice meetings (68\%) were the most common method used in the practice to update the knowledge and skills of dental nurses, followed by experienced staff working with less experienced (47\%), and staff teaching sessions (28\%). A small percentage (11\%) indicated the practice used long distance learning and another $10 \%$ that CAL was used in the practice. The most common course attended was the NVQ Level 3 closely followed by Cardio-Pulmonary Resuscitation.

The question on preference for nurse training (Fig. 5) showed that 53\% of dental nurses preferred in-house training whilst 34\% opted for course attendance. The remainder (13\%) thought a mixture was best. Less than one quarter (23\%) had been involved in audit projects in the practice with 59\% of these collecting data.
Only $11 \%$ said that they had PDPs for the academic year 2005/6 and even fewer (7\%) that they had access to the Section 63 bi-annual courses booklet distributed by the Deanery to all GDPs. Thirtyseven percent specified that there was an appraisal system in place in the practice and 28\% that they had been appraised within the previous two years.

\section{PERCEPTIONS OF THE EDUCATIONAL NEEDS OF DCPS \\ GDPs}

Less than half (40\%) replied to the question regarding the training needs of their dental nurses. Just over a third of this group suggested infection control and 25\% referred to patient management and radiography. Respondents identified a number of other training needs including stress management, resuscitation, materials, health and safety, medical emergencies, practice management and sedation.

Just over half of the respondents specified ways in which the Deanery could best provide education for dental nurses. A wide range of suggestions were made: local courses, evening courses, courses of a similar format to GDPs', lecturers coming into the practice, synchronised courses for the whole dental team, distance learning/e-learning and courses specifically for dental nurses.

Individual respondents provided a number of comments. For example, 'Are courses needed for experienced dental nursing staff?', 'Provide a skills centre dedicated to dental nursing,', 'Regular annual courses at same time every year' and 'Regular, accessible and well publicised'. Three-quarters of those who replied to the question on the provision of funding for dental nurse courses specified that it should come from the Government/Primary Care Trusts.

\section{Dental nurses}

Less than half (41\%) of dental nurses offered example of the types of courses they would like to attend, with the highest percentage (28\%) suggesting refresher courses or general update courses. Fourteen percent suggested new materials and product updates with only $12 \%$ specifying cross-infection control. A range of other courses were proposed, including radiation regulations and radiography, oral health education, implant dentistry, reception skills, first aid, CPR, dental and medical emergencies, and orthodontics. 


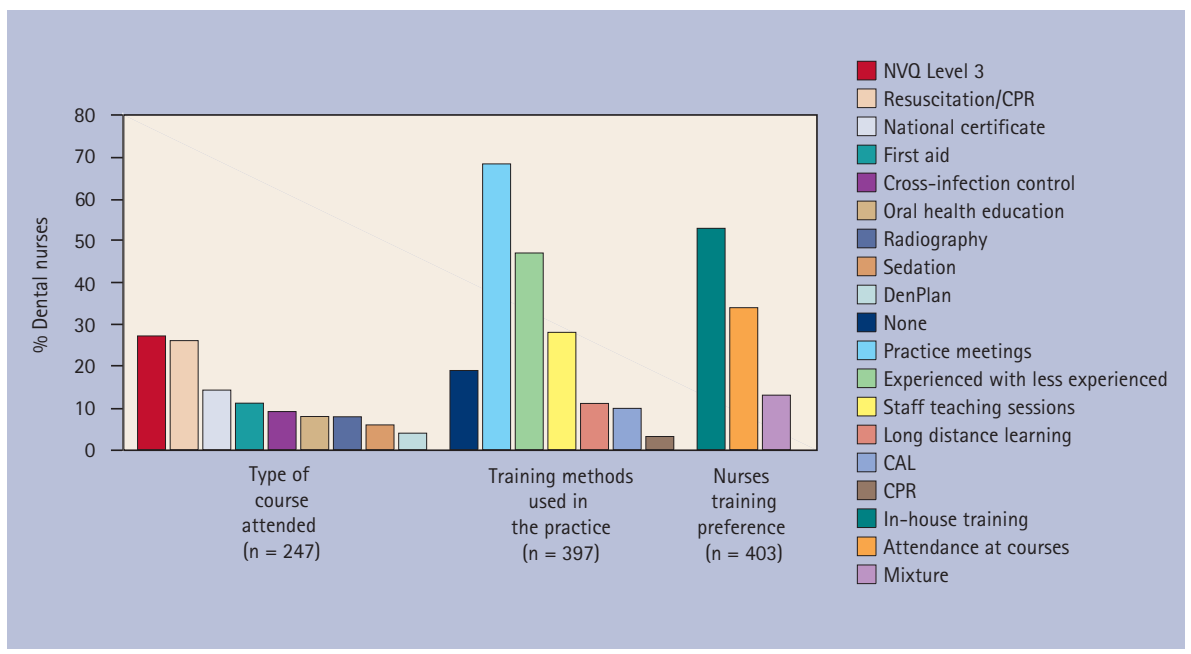

Fig. 5 Dental nurse training

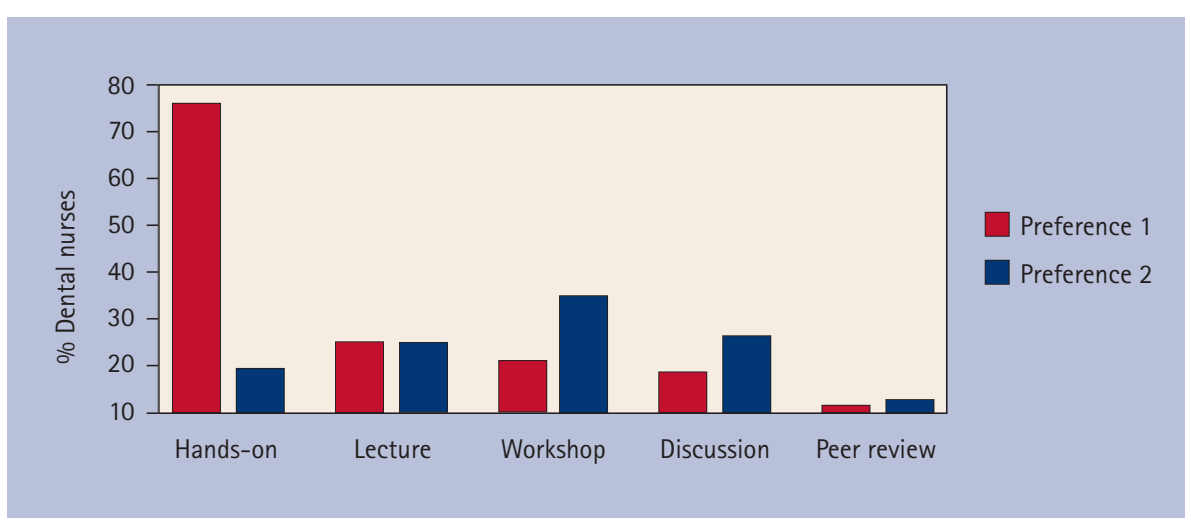

Fig. 6 Dental nurses' preference for course format $(n=392)$

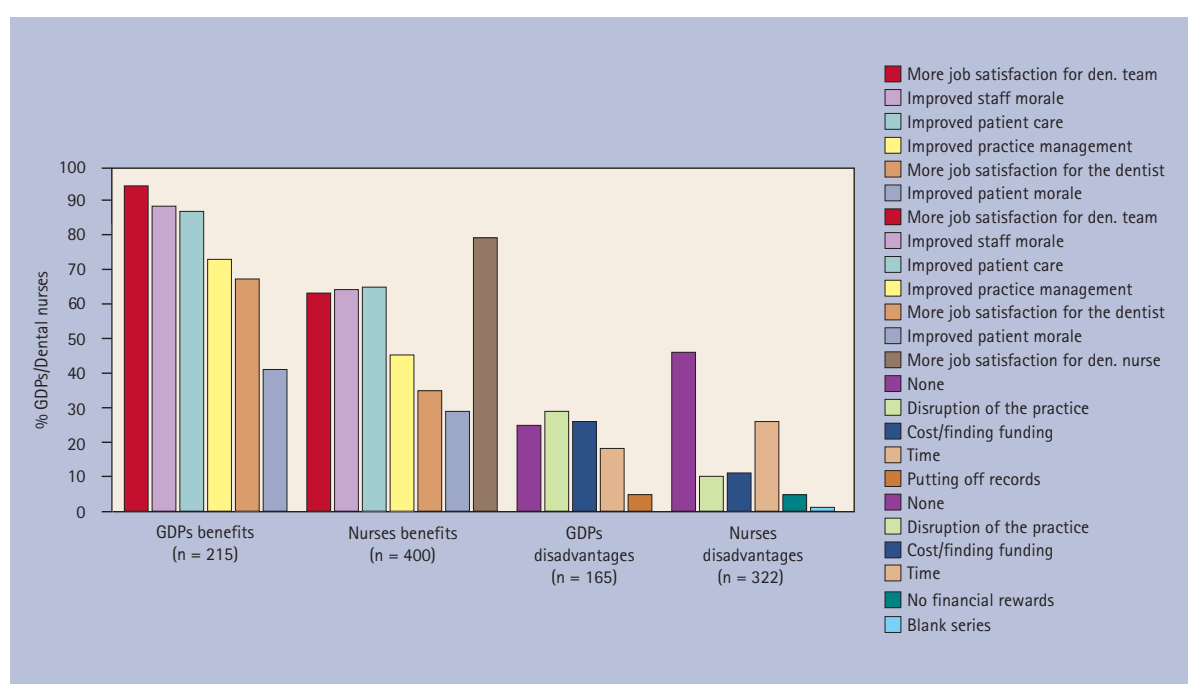

Fig. 7 Benefits and disadvantages of CPD for DCPs

The overwhelming response with regard to which type of course format would best meet their training needs was for hands-on (77\%), with 17\% indicating they preferred a lecture format as their first preference. However, 29\% indicated a workshop format as their second preference (Fig. 6).

Seventy-six percent of dental nurse respondents replied to the question '...what further training away from $43 \%$ of this group replying 'none' or 'don't know'. However, 32\% were aware that a radiography courses was available for dental nurses, $22 \%$ an oral health education course while 12\% mentioned a sedation course and 5\% an orthodontic course. Other suggestions included a hygienist course, therapist course, implant course, infection control and special needs dentistry. the practice is available to you?' with
PERCEPTIONS OF ADVANTAGES, DISADVANTAGES AND BARRIERS TO LIFELONG LEARNING FOR DCPS GDPs

Ninety-four percent of respondents thought lifelong learning for DCPs would result in more job satisfaction for the dental team whilst 88\% thought there would be a rise in staff morale and improvement in patient care. Other benefits included improvement in practice management (73\%), more job satisfaction for the dentist (67\%) and improved patient morale $(41 \%)$. Out of the $66 \%$ who responded to the question on the disadvantages of lifelong learning for DCPs, 25\% thought there were no disadvantages, whereas $26 \%$ stated the cost would be prohibitive and 29\% identified disruption to the practice. Other disadvantages included lack of time, training which is not local, finding appropriate courses and causing a problem with recruitment (Fig. 7). Time, cost, access to courses and family commitments were given as the main barriers to continuing education for DCPs.

\section{Dental nurses}

Seventy-nine percent of dental nurse respondents thought continuing education would result in more job satisfaction for them and 64\% that staff morale would improve. Sixty-five percent said that patient care would improve and $63 \%$ that the dental team would benefit. Other benefits included improvement in practice management (45\%), more job satisfaction for the dentist (35\%), and improved patient morale (29\%).

Out of the $79 \%$ who responded to the question on the disadvantages of lifelong learning for DCPs, 45\% reported there were no disadvantages, whereas $26 \%$ thought finding time would be a problem. Eleven percent considered that cost would be prohibitive and 10\% disruption to the practice. Other disadvantages included no financial rewards, family commitments, lack of time, training which is not local, dentists' attitudes and finding appropriate courses (Fig. 7). Time, cost, family commitments and dentist attitudes were the main barriers to continuing education for dental nurses.

\section{ATTITUDES AND OPINIONS OF GDPS AND} DENTAL NURSES TOWARDS CPD

The opinions of GDPs and dental nurses were sought on a variety of issues 


\begin{tabular}{|c|c|c|}
\hline & GDPs & Dental nurses \\
\hline CPD for DCPs will benefit dental nurses & & $80(n=404)$ \\
\hline $\begin{array}{l}\text { Dental nurses are entitled to protected time for CPD within } \\
\text { normal working hours }\end{array}$ & $57(n=241)$ & $92(n=402)$ \\
\hline CPD for DCPs will benefit the dentist & $80(n=236)$ & $83(n=400)$ \\
\hline Each member of the dental team is responsible for his/her own CPD & $54(n=239)$ & $53(n=403)$ \\
\hline $\begin{array}{l}\text { The dentist, as team leader is responsible for ensuring all his/her } \\
\text { staff participate in CPD }\end{array}$ & $52(n=241)$ & $73(n=403)$ \\
\hline Training is more effective when it takes place in the practice setting & $44(n=243)$ & $60(n=401)$ \\
\hline $\begin{array}{l}\text { Ideas presented during training away from the practice are } \\
\text { beneficial to the practice }\end{array}$ & $79(n=244)$ & $36(n=402)$ \\
\hline $\begin{array}{l}\text { The delivery of training in the practice is more effective if given } \\
\text { by an individual from outside the practice }\end{array}$ & $52(n=244)$ & $52(n=403)$ \\
\hline $\begin{array}{l}\text { An appraisal system is useful for determining strengths } \\
\text { and weaknesses }\end{array}$ & $74(n=244)$ & $76 \%(n=405)$ \\
\hline
\end{tabular}

(Table 1). Ninety-two percent of dental nurse respondents thought dental nurses were entitled to protected time for CPD within normal working hours compared to $57 \%$ of GDPs. Seventy-three percent of dental nurses compared to 52\% of GDPs thought the dentist as a team leader should be responsible for ensuring all his/her staff participate in CPD. Only $36 \%$ of dental nurses compared to $79 \%$ of GDPs thought ideas presented during training away from the practice were beneficial to the practice whereas 60\% of dental nurses compared to $44 \%$ of GDPs regarded training as more effective when it took place in the practice setting.

\section{DISCUSSION}

The sample

The study is notable for a high response rate from both sample groups, which adds strength to the reliability of the results.

\section{Profile of GDPs}

The majority of GDPs were principals and worked in general practices employing three or more dentists. Five percent specialised with 11 specialising in orthodontics and two in implant dentistry. Twenty-four percent had further qualifications but only 25\% said they had personal development plans for 2004/5. An overwhelming majority of GDPs (92\%) saw themselves as working in mixed practices of private and NHS patients. At the time of the study, 7\% of GDPs were fully NHS with a further 57\% treating three quarters of their patients under NHS contracts. Only one dentist indicated that his practice was 100\% private. This is comparable to a study carried out by Burke et al. ${ }^{4}$ which found that $80 \%$ of practitioners were working in group NHS practices.

\section{Profile of the dental nurses}

The survey provided interesting information about the profile of dental nurses working in Yorkshire. Nearly $60 \%$ of dental nurse respondents held a dental nurse qualification, which compares favourably with Sprod and Boyles' findings of $50 \% 5$ and an 0xford study ${ }^{6}$ carried out in 2002 , which found that $60 \%$ of dental nurses had no formal qualifications. Thirty percent of practices employed only qualified dental nurses which again compares favourably with Burke et al.' $\mathrm{s}^{5}$ study which showed that $18 \%$ of practices employed qualified dental nurses only. More than half (60\%) worked fulltime with $45 \%$ in practice for more than 10 years. However, it is of note that only $9 \%$ had worked at the same practice for more than 10 years.

\section{Views of GDPs and dental nurses to lifelong learning}

There was general agreement about the existence of computer facilities in the practice: $80 \%$ of GDPs and $77 \%$ of dental nurses had them. However, fewer nurses had access to the Internet and email $29 \%$ and 25\% respectively - compared to $50 \%$ of GDPs. Sixty-seven percent of GDPs indicated that they had access to CAL programs compared to $25 \%$ of dental nurses. Burke et al. ${ }^{5}$ found low usage amongst older GDPs but in this study $68 \%$ of GDPs over 45 years of age indicated that they had access to CAL programs. There was some disagreement over frequency of team meeting with $89 \%$ of GDPs and 77\% of dental nurses indicating that meetings were held in the practice for the whole dental team. Only $3 \%$ of dental nurses said they were not encouraged to give their opinions. The main topic discussed at team meetings was the smooth running of the practice, including patient and staff complaints. The second most frequently discussed topic was the educational needs of other team members. Thereafter, differences emerged between the two groups. Dental nurses suggested infection control, patient care and health and safety were frequently discussed whereas GDPs identified audit projects, clinical techniques, financial management and educational needs of the dentists. Although audit projects were discussed at team meetings very few dental nurses (23\%) said they were involved in the carrying out of audit in the practice with the majority of these acting as data collectors.

Opinions on continuing education in the practice varied widely between the two groups. Although 52\% of GDPs stated they had problems finding courses for their dental nurses, as many as 92\% reported that their dental nurses had attended educational courses during the previous three years. This was in contrast to the dental nurse respondents' replies where only $62 \%$ stated they were attending or had attended courses. Significantly, 35\% of unqualified dental nurses reported that their course attendance was to gain the NVQ 3 or National Certificate. It was disappointing to find that only $7 \%$ of dental nurses had access to the courses booklet produced bi-annually by the Deanery.

There was a marked difference with regard to training priorities. Fifty-three percent of nurses preferred in-house training whereas only 26\% of GDPs stated a preference for in-house training for their dental nurses. Fifty-one percent of GDPs thought there was an appraisal system in situ for the dental nurses but only $28 \%$ of dental nurses said they had undergone appraisal within the previous 
two years. Very few dental nurses had personal development plans and only $24 \%$ of GDPs indicated that they had formal training plans drawn up for their dental team. When asked about methods used in the practice to update the knowledge and skills of the dental nurse, 77\% of GDPs specified amongst other things experienced staff working with the nonexperienced whereas less that half of the dental nurses indicated this was so. There were also a number of other discrepancies in this area: 63\% of GDPs said dentist provided teaching sessions to update their nurses whereas only $28 \%$ of dental nurses indicated this. Furthermore, 57\% of GDPs reported that an outsider provided teaching sessions in the practice for updating purposes whereas only $4 \%$ of dental nurses indicated that this was the case.

\section{Educational needs of dental nurses}

One of the main aims of the study was to ascertain the educational needs of dental nurses, yet questionnaire responses showed that the majority of dental nurses were unable to assess their requirements. Forty-three percent of respondents did not know what further education courses were available to them and only $40 \%$ replied to the question asking them for course suggestions. Most of these listed general update courses with 12\% mentioning infection control and $11 \%$ computer skills. However, the majority of dental nurse respondents clearly preferred hands-on courses with only $17 \%$ specifying a lecture format. GDPs' responses to the question on the educational needs of their dental nurses' were also disappointing with only $40 \%$ making specific suggestions. These included infection control, patient management, radiography, stress management and cardio-pulmonary resuscitation. Again less than half of the GDP respondents offered suggestions as to how the Deanery could best provide education for dental nurses and most of these were around timing and course location. A few dentists argued that dental nurse and GDP courses should be synchronised and that courses could be run for the whole dental team. Not surprisingly, the majority of GDPs specified that dental nurses' courses should be government funded.

\section{Barriers to CPD for DCPs}

It was not unexpected to find that time, cost, access to courses and family commitments were seen as the main barriers to the continuing professional development of dental nurses. It was interesting to note that $45 \%$ of dental nurse respondents thought there were no disadvantages to lifelong learning for DCPs compared to $25 \%$ of GDPs. A rating scale ranging between 'strongly disagree' to 'strongly agree' was used to determine attitudes and opinions of GDPs and dental nurses on a number of statements concerning continuing professional development for DCPs. The main source of disagreement between dental nurses and GDPs was on the issue of protected time to attend courses. Eightyseven percent of dental nurses agreed or strongly agreed that they are entitled to protected time compared to $57 \%$ of GDPs. Seventy-three percent thought the dentist as the team leader is responsible for ensuring his/her staff participate in CPD compared to 52\% of GDPs. It was noted above that dental nurses preferred in-house training to course attendance and this is borne out by only $36 \%$ agreeing that ideas presented during training away from the practice was beneficial to the practice as compared to $60 \%$ agreeing that training is more effective when it takes place in the practice setting.

The Representative Body of the British Dental Association ${ }^{7}$ stated in 2001 that dentists have an important role to play in supporting the continuing professional development of the whole team, through appropriate attitudes to giving study leave and good employment practices generally, including training-needs assessments, appraisals, etc. A small proportion (18\%) of dental nurses suggested that dentist attitudes were not encouraging and dentists were very reluctant to allow them to have time off for continuing education purposes. A further 10\% expressed worries that the disruption to the practice and resulting conflict amongst staff within the practice would be significant.

\section{CONCLUSIONS}

This study has highlighted a number of issues around continuing professional development for DCPs. These are:

- A marked discrepancy between GDPs and dental nurses' perceptions of dental nurses needs and preferences for continuing education

- A distinct lack of a culture of con- tinuing professional development for DCPs within practices despite the fairly high percentage of qualified or qualifying dental nurses

- A lack of activities that would encourage dental nurse education, for example the use of appraisals to assess needs, having formal training plans in situ, the use of comput ers for computer assisted learning, and involvement in quality assurance tools eg clinical audit

- A lack of knowledge on the part of the majority of dental nurses about what type of further education was available to them and what their educational needs were.

Nevertheless, the vast majority of dental nurses felt they would benefit from continuing education with most preferring a hands-on training format with training taking place in the practice setting. For both GDPs and dental nurses, time or lack of it was the greatest barrier to CPD for DCPs. Most dental nurses and a good proportion of GDPs believed that dental nurses were entitled to protected time for training purposes. These views should be given careful consideration in any future proposals for dental nurse training programmes.

The study also found that retention of dental nurses was a problem for many practices. If continuity is an important component in the development of good practice then this issue needs addressing. Overall, the survey findings indicate that there is a need to promote an ethos of lifelong learning within the practice setting for the whole dental team.

We would like to take the opportunity to thank the dental nurses and general dental practitioners who gave up their time to complete and return the questionnaires. Without their help, this study would not have been possible.

1. Kelly M, Steele J, Nuttall N et al. Adult dental health survey: oral health in the United Kingdom 1998. London: The Stationery Office, 2000.

2. GDC Gazette Spring 2005. p 13.

3. Cannell P. Delivery of postgraduate dental education to meet the needs of general dental practice - A case study. Br Dent J 2005; 198: 367-369.

4. Burke F J T, Wilson N H F, Christensen G J et al. Contemporary dental practice in the UK: demographic data and practising arrangements Br Dent J 2005; 198: 39-43.

5. Sprod A, Boyles J. The workforce of professionals complementary to dentistry in the general dental services: a survey of general dental practices in the South West. Br Dent J 2003; 194: 389-397.

6. John J H, Thomas D, Richards D et al. Regulating dental nursing in the UK Br Dent J 2002: 193: 207-209.

7. British Dental Association. February 2001. 